\title{
Antigenic liposomes displaying CD22 ligands induce antigen-specific B cell apoptosis
}

\author{
Matthew S. Macauley, ${ }^{1}$ Fabian Pfrengle, ${ }^{1}$ Christoph Rademacher, ${ }^{1}$ Corwin M. Nycholat, ${ }^{1}$ \\ Andrew J. Gale, ${ }^{2}$ Annette von Drygalski, ${ }^{2,3}$ and James C. Paulson ${ }^{1}$ \\ 1Department of Chemical Physiology, ${ }^{2}$ Department of Molecular and Experimental Medicine, The Scripps Research Institute, La Jolla, California, USA. \\ 3UCSD, Division of Hematology/Oncology, San Diego, California, USA.
}

\begin{abstract}
Antibodies confer humoral immunity but can also be harmful when they target an autoantigen, alloantigen, allergen, or biotherapeutic. New strategies are needed for antigen-specific suppression of undesired antibody responses, particularly to $T$ cell-dependent protein antigens, because they elicit $T$ cell help. Here we show that liposomal nanoparticles, displaying both antigen and glycan ligands of the inhibitory coreceptor CD22, induce a tolerogenic program that selectively causes apoptosis in mouse and human B cells. These SIGLEC-engaging tolerance-inducing antigenic liposomes (STALs, where SIGLEC is defined as sialic acid-binding Ig-like lectin) induced robust antigen-specific tolerance to protein antigens in mice, preventing subsequent immune response to challenge with the same antigen. Since development of inhibitory antibodies to FVIII is a serious problem in treatment of hemophilia A patients, we investigated the potential of this approach for inducing tolerance to FVIII in a hemophilia mouse model. STALs prevented formation of inhibitory FVIII antibodies, allowing for effective administration of FVIII to hemophilia mice to prevent bleeding. These findings suggest that STALs could be used to eliminate or prevent harmful B cell-mediated immune responses.
\end{abstract}

\section{Introduction}

Unwanted humoral immune responses to protein antigens are responsible for numerous medical conditions in the areas of autoimmunity (1), transplantation (2), allergies (3), and biotherapeutics (4). Current treatment options largely rely on immunosuppressive drugs or immunodepletion therapy, but these approaches can compromise immunity $(5,6)$. A more desirable approach is to silence or delete the antigen-reactive lymphocytes in a manner that preserves protective immunity (7). Several approaches for inducing antigenspecific tolerance have shown some promise (8-14). One, termed antigen-specific immunotherapy (SIT), involves sustained high doses of the antigen administered over the course of months to years (8, $9)$. Another involves the expression or attachment of the antigen to syngeneic cells $(10,11)$. In all these approaches, the mechanism of tolerance induction is thought to have a direct effect on antigen-specific $T$ cells or an induction of regulatory $T$ cells $(10,14)$. As an alternative to $T$ cell-directed therapy, targeting the antigen-reactive B cells offers a more direct approach for systematic induction of humoral tolerance to the desired antigens. Indeed, B cells are the progenitors of antibody-secreting plasma cells and participate in nonhumoral immune responses through the release of cytokines $(15,16)$. However, methods to directly tolerize $\mathrm{B}$ cells in an antigen-specific manner are lacking.

An attractive approach to inducing B cell tolerance is to exploit natural mechanisms that suppress B cell activation. B cells express a host of B cell receptor (BCR) inhibitory coreceptors, which help set a threshold for activation (17). Among them are CD22 and SIGLEC-G (SIGLEC-10 in humans), members of the SIGLEC (sialic acid binding Ig-like lectin) immunoglobulin family that recognize sialic acid-containing glycans of glycoproteins and glycolipids as ligands (18-20). Mice deficient in both CD22 and SIGLEC-G acquire autoantibodies as they age, demonstrating that their combined activities suppress B cell activation to self antigens (21). Sup-

Conflict of interest: The authors have declared that no conflict of interest exists. Citation for this article: J Clin Invest. doi:10.1172/JCI69187. pression of BCR signaling by CD22 requires spatial proximity to the BCR, resulting in its phosphorylation by Scr family kinases and recruitment of phosphatases $(22,23)$. In resting B cells, however, the majority of CD22 is not colocalized with the BCR, but is largely in clathrin-enriched microdomains $(24,25)$, and following ligation of the BCR by a soluble antigen, CD22 is also excluded from activation rafts (26).

Since the majority of CD22 is not associated with the BCR, circumstances that enforce the association of CD22 with the BCR should amplify its inhibitory effect on B cell activation. Evidence that this is the case was first demonstrated through crosslinking of CD22 and BCR with antibodies on a bead (22). In vitro studies by Lanoue et al. suggested that this is relevant in the context of $\mathrm{B}$ cells reactive to a cell-surface antigen, where endogenous sialic acid ligands on the antigen-expressing cells could recruit CD22 to the site of antigen contact and dampen $B$ cell activation (27). More recently, 2 studies used synthetic polymers displaying the T-independent antigen nitrophenol (NP) and glycan ligands of CD22, showing that physically tethering CD22 and the BCR can suppress B cell activation $(28,29)$. Surprisingly, mice immunized with polymers displaying both NP and CD22 ligand not only failed to produce anti-NP antibodies, but also failed to respond to subsequent challenges with a polymer containing NP alone (28). However, tolerance was not observed when the initial immunization was carried out with adjuvant (28), raising doubt that this approach would work with $\mathrm{T}$ cell-dependent (protein) antigens since a second signal from helper T cells could blunt the inhibitory effect of CD22.

To investigate the potential for inducing tolerance to protein antigens by enforced ligation of the BCR and CD22, we employed liposomal nanoparticles that display both a protein antigen and CD22 ligands. We found that these SIGLEC-engaging toleranceinducing antigenic liposomes (STALs) induce antigen-specific tolerance to $\mathrm{T}$ cell-dependent antigens in mice via deletion of the antigen-reactive $\mathrm{B}$ cells by apoptosis. The utility of this platform 
for preventing an undesired antibody response is illustrated by complete suppression of anti-FVIII antibodies in a hemophilia mouse model following challenge with human FVIII (hFVIII). Induced tolerance to FVIII and suppression of anti-FVIII antibodies enables protection of mice from bleeding in a tail-cut assay following administration of hFVIII. STALs also induce a tolerogenic program in human primary B cells within both the naive and memory compartments, suggesting that STALs may provide the basis of a strategy for preventing and eliminating harmful antibody responses in humans.

\section{Results}

Tolerogenic liposomes with siglec ligands. Liposomal nanoparticles were selected as a platform for enforced ligation of CD22 to the BCR because of their validated in vivo use and the robust methods that exist for covalently linking proteins and glycan ligands to lipids for incorporation into the membrane (30-32). Accordingly, STALs were constructed that displayed both CD22 ligand and antigen (Figure 1A). The effects of STALs were compared with those of liposomes displaying antigen alone (immunogenic liposomes). For initial studies, we used a high-affinity siglec ligand,

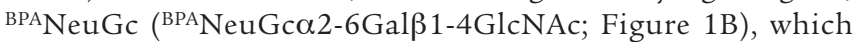
binds to murine CD22 with 200-fold higher affinity than its natural ligand (NeuGco2-6Gal $\beta 1-4 G l c N A c ;$ Figure $1 \mathrm{~B}$ ) and has only a small degree of crossreactivity with SIGLEC-G $(28,33)$.

This platform was initially validated using the T-independent antigen NP to compare with previous results using a polyacrylamide polymer (28). Mice injected with STALs bearing NP had a dramatically inhibited anti-NP response (both IgM and IgG isotypes) compared with immunogenic liposomes and failed to respond to 2 subsequent challenges with immunogenic liposomes (Figure 1C). In contrast, Cd22-KO mice treated with STALs displayed no tolerization to NP upon a subsequent challenge; thus, tolerance to NP was induced in a CD22-dependent manner.

We next formulated STALs displaying hen egg lysozyme (HEL) (Supplemental Figure 1; supplemental material available online with this article; doi:10.1172/JCI69187DS1) to investigate the potential to induce tolerance to a $T$ cell-dependent antigen. Using the same experimental design, STALs induced robust tolerance of C57BL/6J mice to HEL in a CD22-dependent manner (Figure 1D). Experiments on tolerization to HEL were repeated with STALs

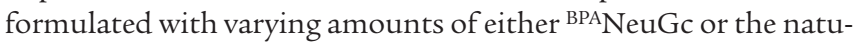
ral ligand NeuGc. At the end of the 44-day experiment involving 2 challenges with immunogenic liposomes on days 15 and 30, a dose-dependent effect on antibody suppression was apparent for both ligands (Figure 1E). The 2 orders of magnitude difference in $E C_{50}$ (half-maximal effective concentration) between the 2 ligands is consistent with their known affinities for CD22 (33). Maximal tolerization to HEL required 2 weeks to develop and diminished slowly over 4 months (Figure 1F).

STALs induce apoptosis of antigen-reactive B cells. The mechanism of tolerance induction was investigated using transgenic HEL-reactive $\left(\mathrm{IgM}^{\mathrm{HEL}}\right) \mathrm{B}$ cells from MD4 mice (34). STALs completely abrogated in vitro activation of $\operatorname{IgM}^{\mathrm{HEL}} \mathrm{B}$ cells, as judged by calcium flux, CD86 upregulation, and proliferation (Figure 2, A-C). Suppressed activation was $\mathrm{CD} 22$ dependent, as shown with $\operatorname{IgM}^{\mathrm{HEL}} \mathrm{B}$ cells on a Cd22-KO background (Figure 2A and Supplemental Figure 2, A-C). Inhibition required presentation of both ligand and antigen on the same liposome, since a mixture of liposomes displaying either CD22 ligand or antigen alone resulted in no inhibition (Figure 2A).
In proliferation assays (Figure $2 \mathrm{C}$ ), we noticed that cells treated with the STALs decreased in number relative to unstimulated cells. Analysis of percentage of live cells (annexinV-PI-, where PI indicated propidium iodide) revealed a time-dependent decrease in this population (Figure 2D). Culturing cells with anti-CD40 to mimic $\mathrm{T}$ cell help slowed down but did not prevent cell death (Supplemental Figure 3). It is noteworthy that liposomes displaying only CD22 ligand did not activate or affect the viability of B cells.

Next, we examined the fate of $\operatorname{IgM}^{\mathrm{HEL}} \mathrm{B}$ cells adoptively transferred into host mice following immunization with liposomes. Four days after immunization, IgM ${ }^{\text {HEL }}$ B cells from mice immunized with STALs had proliferated far less and were decreasing in number relative to mice immunized with naked liposomes (Figure 2E). After 12 days, IgM ${ }^{\mathrm{HEL}}$ cells $\left(\mathrm{Ly}^{\mathrm{a}+} \operatorname{IgM}^{\mathrm{a}}\right)$ were depleted by greater than $95 \%$ in mice that were immunized with the STALs relative to mice that received naked liposomes (Figure $2 \mathrm{~F}$ ). These in vivo effects were also CD22 dependent (Supplemental Figure 2, D and $\mathrm{E})$.

Impact of STALs on BCR signaling. BCR signaling in IgM ${ }^{\mathrm{HEL}} \mathrm{B}$ cells was analyzed by assessing the phosphorylation status of signaling components by Western blotting at several time points after stimulation with liposomes (Figure 3A and Supplemental Figure 4). STALs gave rise to strong CD22 phosphorylation on all 4 immunoreceptor tyrosine-based inhibitory motif (ITIMs) analyzed, which is consistent with physical tethering of CD22 and the BCR within the immunological synapse. Conversely, phosphorylation of numerous proximal (Syk and CD19) and distal (p38, Erk, JNK, Akt, GSK3 $\beta$, FoxO1, FoxO3a, BIM) BCR signaling components was strongly inhibited by the STALs compared with the liposomes displaying antigen alone at both 3 - and 30-minute time points. In striking contrast, STALs and immunogenic liposomes induced equivalently strong phosphorylation of signaling components in IgM ${ }^{\mathrm{HEL}}$ cells lacking CD22.

Among the affected signaling components, it is striking that STALs induced hypophosphorylation of components in the Akt survival pathway compared with unstimulated B cells. Akt was hypophosphorylated at both the Thr308 and Ser473 sites, while downstream targets of Akt, such as GSK3 $\beta$ and FoxO1/FoxO3a, were also hypophosphorylated. Given that Akt-mediated phosphorylation of the forkhead family of transcription factors controls their cellular location (35), we used confocal microscopy to analyze localization of FoxO1 and FoxO3a (Figure 3B and Supplemental Figure 5). FoxO1 and FoxO3a were notably absent in nuclei of resting IgM ${ }^{\text {HEL }} \mathrm{B}$ cells or cells stimulated with immunogenic liposomes, but strong nuclear staining was evident in cells treated with the STALs. As FoxO1 and FoxO3a regulate the expression of genes involved in cell-cycle inhibition and apoptosis in B cells (35), these results are consistent with STALs inducing a tolerogenic program involving apoptosis.

Tolerance to strong $T$ cell-dependent antigens. To assess the flexibility of STALs, we investigated their ability to suppress antibody production to proteins known to provide strong $\mathrm{T}$ cell help in C57BL/6J and/or BALB/c strains of mice. The STAL formulation was optimized to maximize CD22-mediated tolerance while minimizing $\mathrm{T}$ cell help by varying the amount of HEL on the liposome and titrating the amount of STALs injected during the tolerizing step (Supplemental Figure 6, A and B). Optimized STAL formulations greatly suppressed antibody responses to HEL in BALB/c mice following a challenge with either immunogenic liposomes or soluble protein (Supplemental Figure 6, C and D). Similarly, 
A

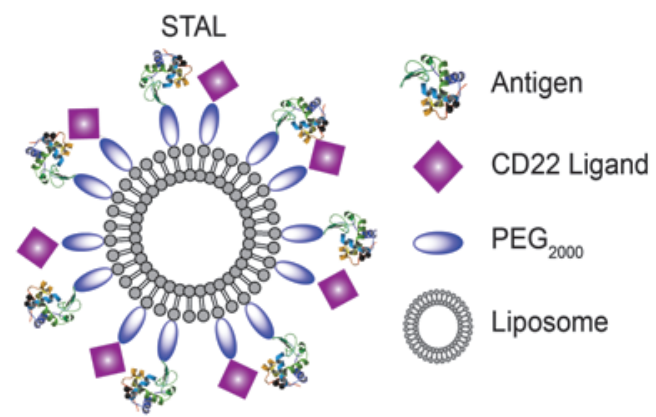

C
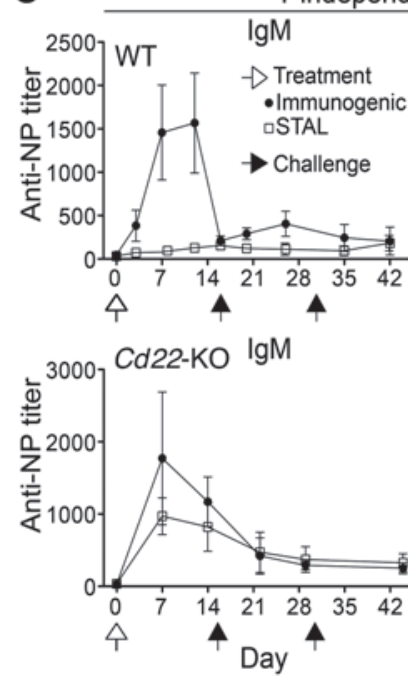

E

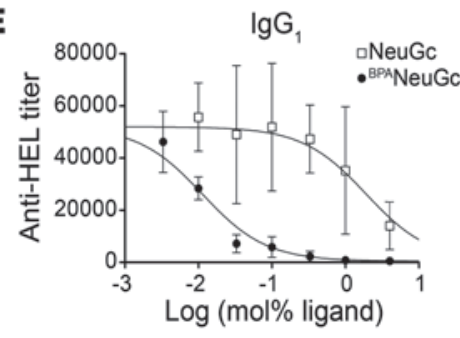

B
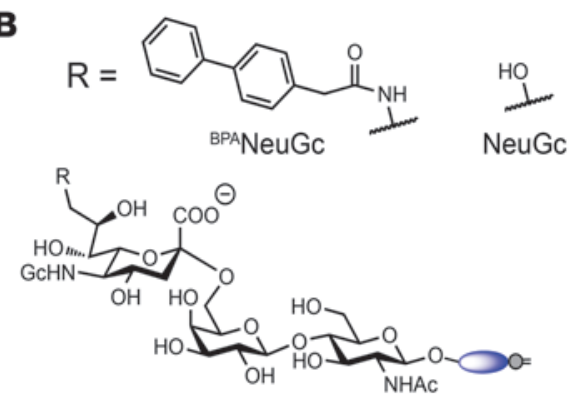

D
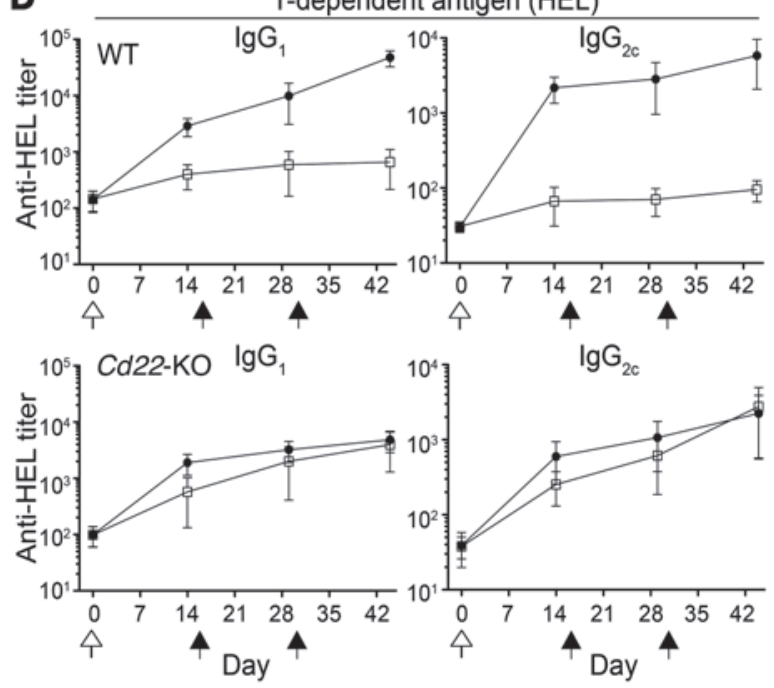

F

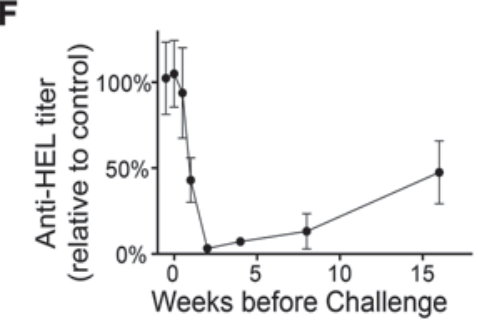

Figure 1

Induction of tolerance with liposomes displaying antigen and CD22 ligands. (A) Schematic of STALs. (B) Chemical structures of CD22 ligands used for studies in mice. (C and D) CD22-dependent induction of tolerance to a T-independent (NP; C) and a T cell-dependent antigen (HEL; D). WT or Cd22-KO mice were treated on day 0 (white arrow) as shown and challenged with the immunogenic liposomes on days 15 and 30 (black arrow). Data represent mean \pm SEM. $(n=8-10)$. (E) Titration of BPANeuGc and NeuGc on STALs. Titers were determined after 2 challenges with immunogenic liposomes on days 15 and $30(n=4)$. $(\mathbf{F})$ Mice were tolerized to HEL at different times relative to the challenge and titers were determined 2 weeks after challenge with immunogenic liposomes and are plotted as percentage relative to immunization of naive mice $(n=4)$. Data represent mean \pm SEM. $(n=4)$.

STALs with OVA, myelin oligodendrocyte glycoprotein (MOG), and FVIII were also tolerogenic, resulting in significantly lower antibody responses following a challenge with the corresponding antigen (Figure 4, A-C). To assess the specificity of tolerization toward the intended antigen, we investigated the response of tolerized mice to a different antigen. Mice subjected to STALs with either HEL or OVA were found to suppress antibody production to that antigen, but there was no effect on the antibody response to the other antigen (Figure 4D). The tolerogenic impact of STALs does not appear to involve induction of suppressor cells, since adoptively transferred splenocytes from a tolerized mouse do not suppress an antibody response to that antigen in recipient mice (Supplemental Figure 7). Therefore, induction of antigenspecific tolerance by STALs is B cell intrinsic.

Bleeding protection in hemophilia mice. Having demonstrated that STALs suppress antibody production to human FVIII in WT mice, we investigated the impact of tolerization in FVIII-deficient mice, which serve as a model of hemophilia A. FVIII-deficient mice on a BALB/c background were used because they are highly sensitive to developing inhibitory antibodies toward FVIII, which 
A
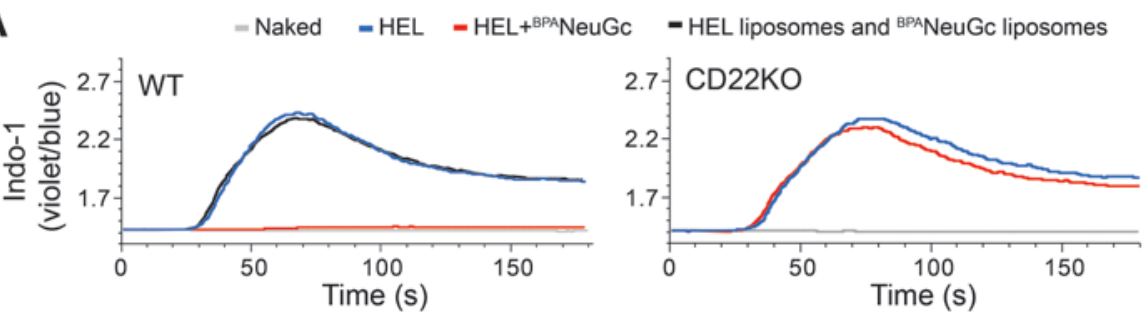

B
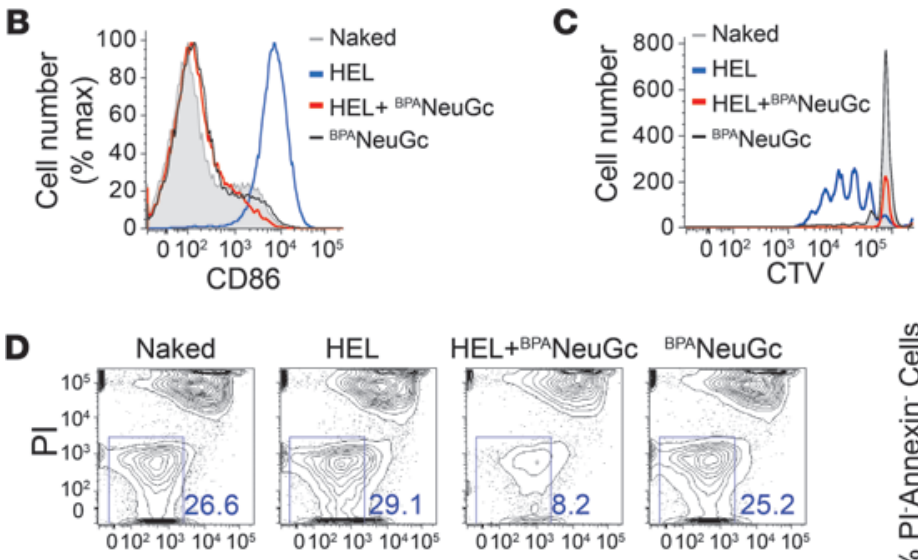

AnnexinV

$\mathbf{E}$

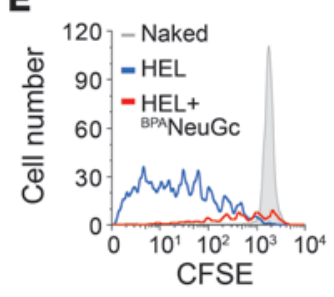

$\mathbf{F}$

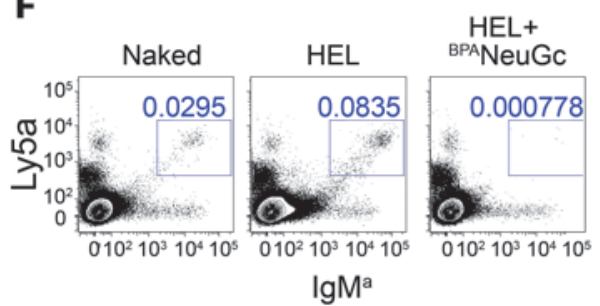

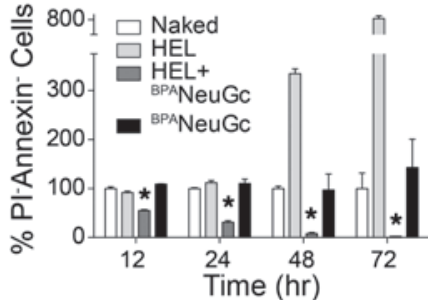

Time (hr)

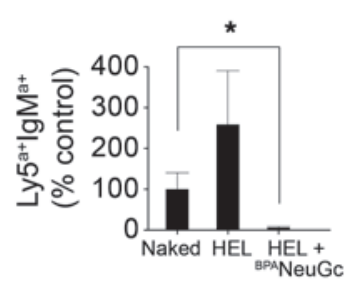

Figure 2

STALs strongly inhibit BCR signaling and cause apoptosis. (A) Calcium flux in IgM ${ }^{H E L}$ B cells stimulated with the indicated liposomes. (B) CD86 upregulation of IgM ${ }^{H E L} B$ cells 24 hours after stimulation with the indicated liposomes. (C) In vitro proliferation of CTV-labeled IgMHEL B cells 3 days after simulation with the indicated liposomes. (D) Annexin V versus PI staining of IgM HEL B cells treated for 24 hours with the indicated liposomes. For quantification over time, the percentages of annexinV-PI- (live) cells are expressed relative to the controls treated with naked liposomes normalized to $100 \%$ at each time point and plotted as the mean \pm SEM $(n=3)$. (E) In vivo proliferation of adoptively transferred CFSE-labeled IgM ${ }^{H E L}$ $B$ cells 4 days after immunization with the indicated liposomes. The same number of total splenocytes was analyzed for each condition $\left(1 \times 10^{6}\right)$ and gated through the $\operatorname{lgM}{ }^{a+}$ Ly5 $5^{a+}$ population. (F) Analysis of the number of adoptively transferred Ly $5^{a+} \operatorname{lgM}^{\text {HEL }} \mathrm{B}$ cells remaining in the spleen of recipient mice 12 days after immunization with the indicated liposomes. Quantitation represents mean $\pm \operatorname{SEM}(n=4) .{ }^{*} P<0.05$.

abrogate reconstitution with FVIII to prevent bleeding (36). Indeed, as shown in Figure 5A, FVIII-KO mice immunized with liposomes displaying FVIII on day 0 and day 15 were unsuccessfully reconstituted with recombinant human FVIII (rhFVIII) on day 30 , since they bled in a tail-cut experiment to an extent similar to that seen in FVIII-KO mice that had not been reconstituted. On the other hand, mice that received STALs on day 0 followed by a challenge with immunogenic liposomes on day 15 were successfully reconstituted with FVIII and were protected from bleeding following a tail cut to a level that was statistically indistinguishable from that of control mice that were reconstituted with FVIII. The levels of anti-FVIII antibodies in the mice from this study correlated with the results from the bleeding assay; mice first treated with STALs prior to a challenge with immunogenic liposomes did not produce a statistically significant increase in anti-FVIII antibodies relative to control mice (Figure 5B). In con- trast, mice that received the immunogenic liposomes on days 0 and 15 had high levels of anti-FVIII antibodies. Thus, STALs are an effective means of suppressing inhibitory antibody formation against the biotherapeutic FVIII.

STALs induce apoptosis in buman naive and memory B cells. To determine whether STALs similarly regulate BCR activation in human B cells, we formulated STALs with lipid-linked anti-IgM or antiIgG Fab fragments as surrogates of protein antigens for ligating the BCR on naive or memory B cells, respectively, and a highaffinity human CD22 ligand termed BPCNeuAc (BPCNeuGco26Galß1-4GlcNAc; Figure 6A and refs. 33, 37). Liposomes displaying anti-IgM or anti-IgG induced robust $B$ cell activation of naive (CD27-CD38 $\left.{ }^{\text {int }}\right)$ and $\operatorname{IgG}$ memory $\left(\mathrm{IgM}^{-} \mathrm{IgD}^{-} \mathrm{CD} 38^{-}\right)$B cells isolated from peripheral blood, respectively (Figure 6B). In contrast, liposomes displaying ${ }^{\mathrm{BPC}} \mathrm{NeuAc}$ and the anti-Ig Fab fragments abrogated $\mathrm{B}$ cell activation of both the naive and memory 
A

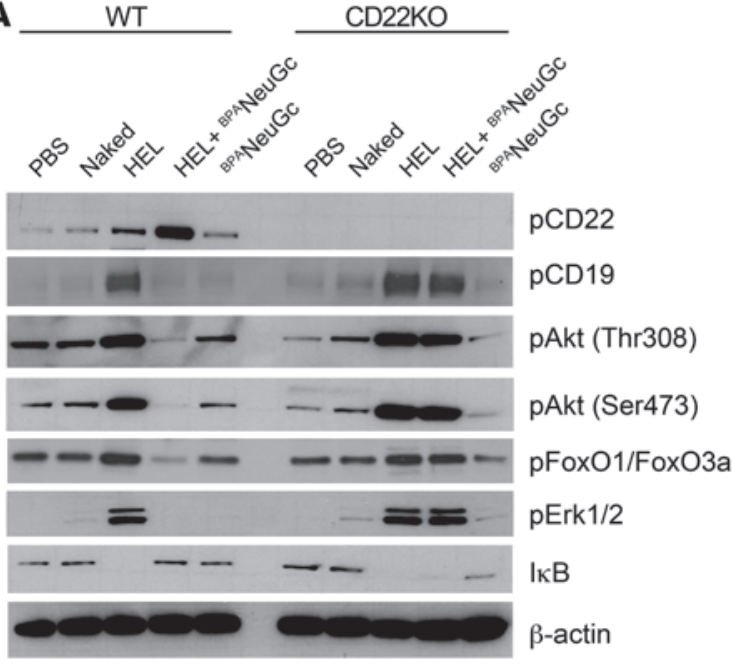

B
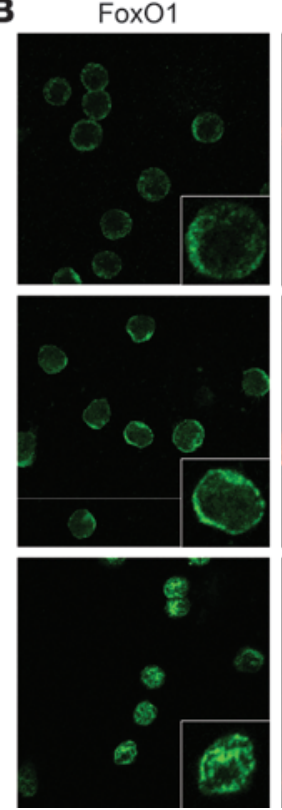

Phalloidin
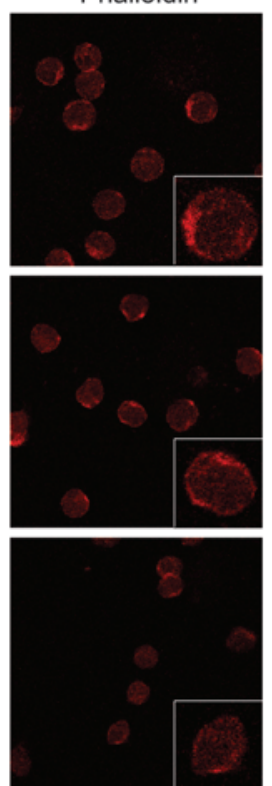

Merge + DAPI
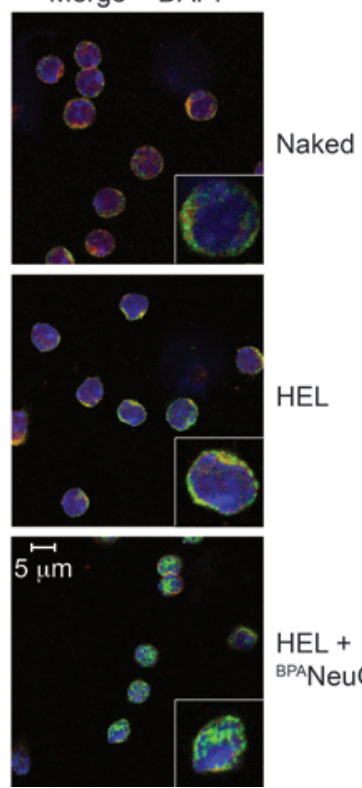

HEL

HEL +

BPANeuGC:

\section{Figure 3}

A CD22-dependent tolerogenic program inhibits basal signaling in the Akt survival pathway and drives nuclear import of FoxO1. (A) Western blot analysis of BCR signaling components in WT and Cd22-KO IgM $\mathrm{IHEL}^{\mathrm{H}}$ cells 30 minutes after stimulation of cells with the indicated liposomes or PBS as a control. STALs inhibit phosphorylation of signaling components of all major BCR signaling pathways and induce hypophosphorylation of Akt and FoxO1 in WT B cells, but not Cd22-deficient IgMHEL B cells. Data are a subset of Supplemental Figure 4. (B) Analysis of FoxO1 staining in IgM ${ }^{H E L} \mathrm{~B}$ cells by confocal microscopy. Cells were stimulated for 2 hours with the indicated liposomes and stained with anti-FoxO1, phalloidin, and DAPI. Inserts are a representative cell at 3 times the magnification. Original magnification, $\times 63$.

cells (Figure 6B). Similarly strong inhibition of BCR signaling was also seen in activation of BCR signaling components (Figure 6C) and expression of CD86 (Figure 6D). To determine whether these STALs also decrease the viability of primary human B cells, we analyzed annexin V and PI staining following 24-hour incubation with liposomes. The number of live cells (annexin $\mathrm{V}^{-} \mathrm{PI}^{-}$) decreased in both naive and memory B cells when incubated with anti-IgM or anti-IgG STALs, respectively, even in the presence of anti-CD40 (Figure 6E). Liposomes displaying anti-IgM and BPCNeuAc or anti-IgG and ${ }^{B P C} \mathrm{NeuAc}$ had no effect on the viability of memory and naive $\mathrm{B}$ cells, respectively, demonstrating that induction of apoptosis requires simultaneous engagement of the BCR and CD22 (Supplemental Figure 8). Interestingly, the STALs had a more profound effect on inhibition of B cell activation and viability in memory B cells despite moderately lower (2- to 4-fold) levels of CD22 expression in this compartment (Figure $6 \mathrm{~F}$ and ref. 38). The combined results show that the impact of STALs on BCR signaling of human B cells is similar to that observed in murine B cells, leading to apoptosis of the cells as a hallmark of tolerance induction.

\section{Discussion}

We describe STALs as a platform for inducing antigen-specific $B$ cell tolerance and demonstrate the potential for biomedical impact by preventing formation of neutralizing antibodies to FVIII in a mouse model of hemophilia. STALs consist of liposomes displaying both CD22 ligands and an antigen, which juxtapose the inhibitory receptor CD22 with the BCR in the context of an immunological synapse and induce a tolerogenic program in B cells. The flexibility of these STALs has enabled us to maximize the tolerogenic signal, which enables tolerization of mice to strong $\mathrm{T}$ celldependent antigens in an antigen-specific manner. Several lines of evidence suggest that tolerance is the direct result of deletion of the antigen-specific B cells from the B cell repertoire. In vitro results clearly demonstrate that tolerogenic liposomes decrease cell viability by inducing apoptosis. Consistent with this finding, STALs strongly inhibit basal signaling in the PI3K/Akt signaling pathway, which is a well-established survival pathway in B cells (39, 40). Extending these observations in vivo, adoptively-transferred antigen-reactive B cells decreased in number upon immunization with the STALs and were nearly fully depleted by day 12 . Therefore, the induction of tolerance appears to be intrinsic to deletion of the antigen-reactive B cells.

The need for general methodologies to induce tolerance to protein antigens is clear in the area of biotherapeutics where antidrug antibodies (ADA) are of considerable concern. Even after extensive efforts to minimize immunogenicity of the biological therapeutics themselves, ADAs still remain an issue in not only decreasing efficacy but, more seriously, causing anaphylaxis $(4,41,42)$. To illustrate the potential therapeutic utility of our STAL platform at inducing antigen-specific B cell tolerization, we applied our approach to a hemophilia mouse model, since anti-FVIII antibodies are a substantial problem for hemophilia A patients that receive FVIII replacement therapy. Remarkably, we found that tolerizing mice to rhFVIII with STALs suppressed anti-FVIII antibodies after a challenge with immunogenic liposomes. Consistent with a lack of inhibitory antibodies in these mice, infused rhFVIII successfully prevented bleeding following 

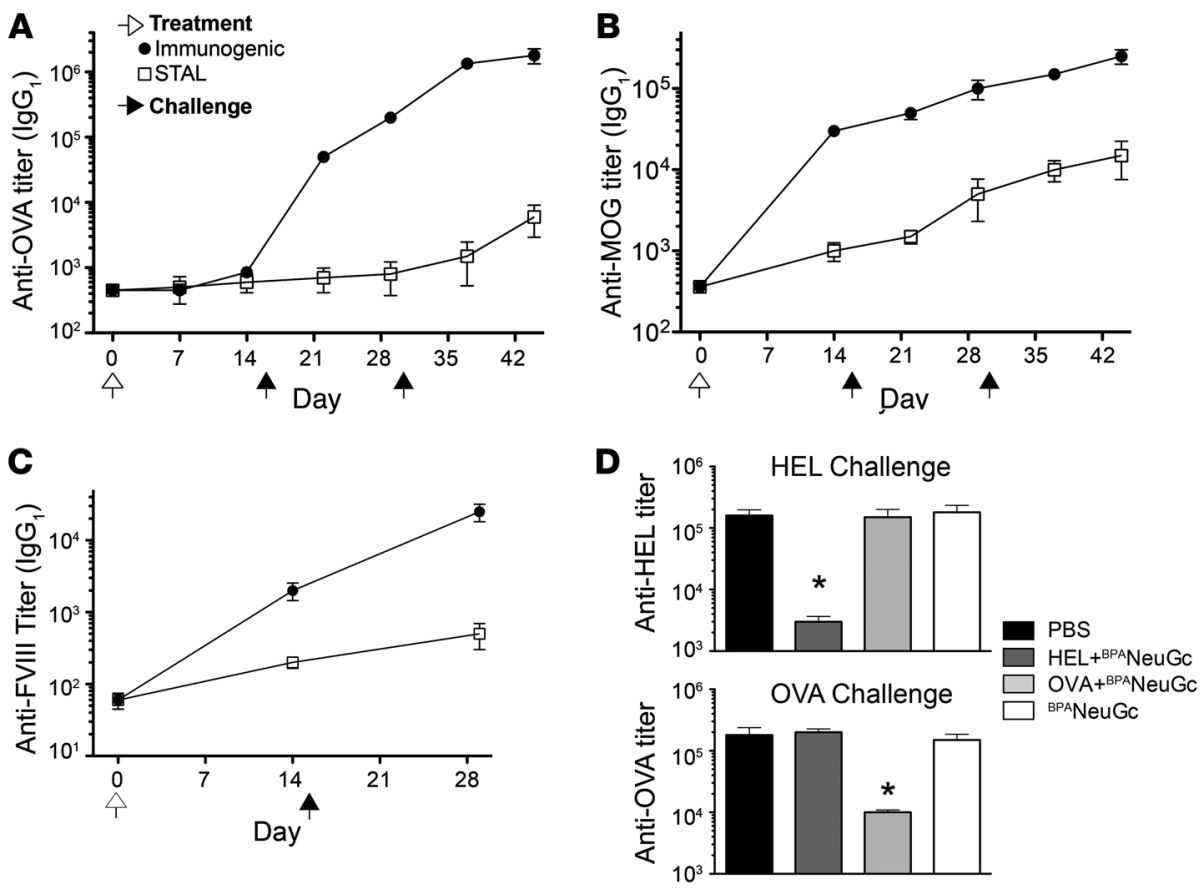

\section{Figure 4}

Antigen-specific tolerization of mice to strong T cell-dependent antigens. (A) Tolerization of OVA in C57BL/6J mice. (B) Tolerization of MOG(residues 1-120) in BALB/c mice. (C) Tolerization of FVIII in $B A L B / c$. (D) Tolerization is antigen-specific. BALB/c mice tolerized to HEL or OVA have normal responses to other antigens. Mice were immunized on day 0 (white arrows) with the indicated conditions, challenged on day 15 with immunogenic liposomes (black arrows), and titers ( $\left.\operatorname{lgG}_{1}\right)$ determined 2 weeks later on day 29. Black arrows show days 15 and 30. All data represent mean \pm SEM $(n=4) .{ }^{*} P<0.05$. tail cut. In patients with hemophilia, inhibitory antibodies develop in approximately $20 \%-30 \%$ of patients shortly after initiation of FVIII therapy $(43,44)$, thereby rendering those patients unresponsive to FVIII-products. The development of inhibitors is the most serious complication in patients with hemophilia, with a high risk of mortality from fatal bleeding. Currently, the only option for achieving immune tolerance in patients with hemophilia A (congenital FVIII deficiency) and inhibitors is immune tolerance induction (ITI), in which high doses of FVIII are administered for prolonged periods of time. Treatment can take 2 years, remains unsuccessful in approximately $30 \%$ of patients, is extraordinarily costly, and cannot be used in a prophylactic manner to suppress the initial development of inhibitory antibodies (9). New therapeutic approaches are therefore highly desirable. In addition to providing general proof-of-principle that STALs are highly efficient in inducing immunological tolerance, we have demonstrated their potential for future therapeutic exploitation in a relevant disease model.

The function of CD22 as an inhibitory B cell coreceptor is thought to be conserved between mice and humans (45). Less clear is whether this function extends to isotype-switched B cells, since there are conflicting reports on this topic (46-48). By linking anti-IgG Fab fragments onto liposomes along with CD22 ligands, we have been able to probe the inhibitory nature of CD22 on memory B cells isolated from human peripheral blood. Our findings clearly reveal that drawing CD22 to the immunological synapse, on either naive or memory human B cells, generates a profound inhibitory effect, which abrogates B cell activation. This inhibition of B cell activation and induction of apoptosis parallels the early events of the tolerogenic program found in murine $B$ cells. Moreover, STALs decreased the viability of human primary $\mathrm{B}$ cells within both the naive and memory compartments. These effects were even more dramatic in memory B cells, suggesting that in addition to preventing a naive response, STALs may also be effective for suppressing a memory B cell response.
While the efficacy of STALs for inducing tolerance in a model of FVIII inhibitors in hemophilia mice illustrates their ability to induce $\mathrm{B}$ cell tolerance in immunologically naive subjects, the full realization of the potential of STALs will require induction of tolerance in a previously sensitized immune system that contains both memory $\mathrm{B}$ and $\mathrm{T}$ cells. Given that maximal tolerance induction in our hands required optimizing the formulation to minimize a $\mathrm{T}$ cell response, it will be of interest to investigate the use of STALs in conjunction with established methods for tolerizing or suppressing $\mathrm{T}$ cell responses $(7,8,10,11,14)$. Targeting both the $B$ cell and $T$ cell compartments may be optimal for antigen-specific tolerization of complex immune disorders such as allergies and autoimmune diseases.

\section{Methods}

Mouse strains. Cd22-KO mice were obtained from L. Nitschke (University of Erlangen, Erlangen, German). WT MD4 transgenic mice (34) were obtained from Jackson Laboratories. FVIII-deficient mice (BALB/c background) were a gift of David Lillicrap (Queen's University, Kingston, Ontario, Canada). WT C57BL/6J and BALB/c mice were obtained from the The Scripps Research Institute (TSRI) rodent breeding colony.

Proteins. HEL and ovalbumin were obtained from Sigma-Aldrich. MOG(residues 1-120) was recombinantly produced in E. coli with an $\mathrm{N}$-terminal polyhistidine tag for purification purposes. Briefly, residues 1-120 of rat MOG were cloned from a rat brain cDNA library (Zyagen) using the following primers: 5 '-GCAGCACATATGGGACAGTTCATAGTGATAGGG-3' and 5'-GCAGACCTCGAGGTAGAAGGGATCTTCTACTTTC- 3 ', where the underlined letters represent the NdeI and XhoI restriction sites, respectively. The PCR product was ligated into PET23a to express a protein with a C-terminal $\mathrm{His}_{6}$-tag and purified on a nickel affinity column (GE Healthcare). rhFVIII was a gift from F. Aswad at Bayer Healthcare. Anti-human IgM and anti-human IgG Fab fragments were obtained from Jackson ImmunoResearch.

Isolation of human B cells. Normal blood was obtained from TSRI's Normal Blood Donor Service. PBMCs were isolated from heperanized blood by isolating the buffy coat using Ficoll-Paque Plus (GE healthcare). B cells were 
A

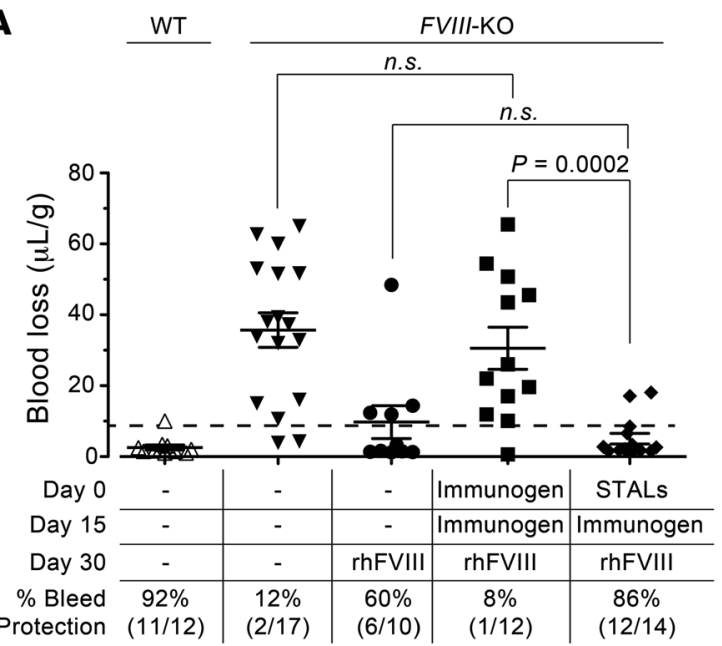

B

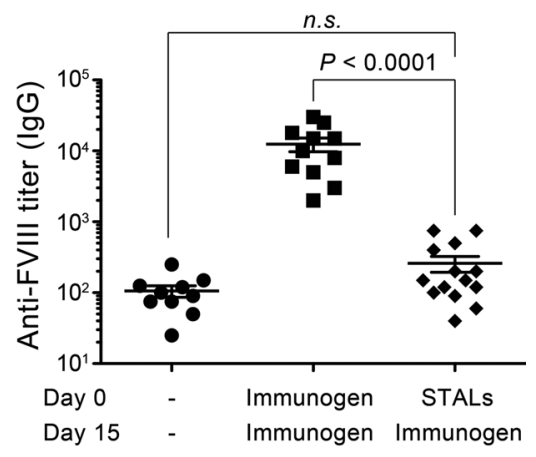

Figure 5

Immune tolerization to FVIII prevents bleeding in FVIII-deficient mice. (A) WT or FVIII-deficient mice were dosed on days 0 and 15 with immunogenic liposomes (Immunogen), STALs, or left untreated. On day 30, mice were reconstituted with rhFVIII at $50 \mathrm{U} / \mathrm{kg}$ or saline. FVIII-deficient mice treated with STALs had significantly less blood loss $(\mu \mathrm{l} / \mathrm{g})$ over 20 minutes following tail clip than mice initially treated with immunogenic liposomes. Percentage of bleeding protection (dashed line) represents blood loss of less than $9.9 \mu \mathrm{l} / \mathrm{g}$ as defined by mean $+3 \mathrm{SDs}$ in WT BALB/c mice. (B) FVIII titers in the 3 reconstituted groups demonstrate that bleeding prevention is accompanied by a significant reduction in anti-FVIII antibodies. Data represent mean \pm SEM. A 2-tailed Student's $t$ test was used to establish the level of significance. NS is defined by a $P$ value greater than 0.05 .

purified by negative selection (Miltenyi Biotec). For Western blot analysis of BCR signaling components, the purified B cells were additionally sorted into either naive (CD27- $\left.\mathrm{CD} 38^{\text {int }}\right)$ or isotype-switch memory $\left(\mathrm{IgM}^{-}\right.$ IgD-CD38-) B cells.

Immunization and blood collection. Whole blood $(50 \mu \mathrm{l})$ was collected from mice via a retroorbital bleed to obtain the serum after centrifugation $\left(17,000 \mathrm{~g}, 1\right.$ minute). Serum was aliquoted and stored at $-20^{\circ} \mathrm{C}$. Liposomes were delivered via the lateral tail vein in a volume of $200 \mu \mathrm{l}$. For studies involving a challenge with soluble (nonliposomal) antigen, mice were injected with $200 \mu \mathrm{g}$ of HEL dissolved in HBSS and delivered intraperitoneally.

Bleeding assays in FVIII-deficient mice. Mice were reconstituted with $200 \mu \mathrm{l}$ of rhFVIII (Kogenate, Bayer Healthcare) or saline 1 hour prior to tail cut. rhFVIII was dosed at $50 \mathrm{U} / \mathrm{kg}$ using a retroorbital intravenous injection. Following 1 hour, mice were anesthetized and the distal portion of the tail was cut at 1.5 - $\mathrm{mm}$ diameter and immersed in a predefined volume of saline for 20 minutes. The solution of saline was maintained at $37^{\circ} \mathrm{C}$. Hemoglobin concentration in the solution was determined after red cell lysis with $2 \%$ acetic acid and quantified by $\mathrm{A}_{405}$. Hemoglobin concentration against a known standard was used to calculate blood loss/g mouse weight and expressed in $\mu \mathrm{l} / \mathrm{g}$, assuming a hematocrit of $46 \%$ for a normal mouse. Blood loss in WT BALB/c mice injected with $200 \mu \mathrm{l}$ saline served as a control. Mice were considered protected if blood loss was below the mean blood loss plus 3 SD observed in WT BALB/c mice (49).

Fluorescent labeling of $B$ cells. B cells were purified by negative selection using magnetic beads (Miltenyi). Purified IgM ${ }^{\mathrm{HEL}} \mathrm{B}$ cells $\left(10 \times 10^{6} \mathrm{cells} /\right.$ $\mathrm{ml})$ were fluorescently labeled with either CFSE $(6 \mu \mathrm{M})$ or CTV $(1.5 \mathrm{M})$ (Invitrogen) in HBSS (7 minutes, room temperature [RT]) with mixing every 2 minutes. Reactions were quenched by the addition of HBSS containing $3 \%$ FBS and centrifuged ( $270 \mathrm{~g}, 7$ minutes) and washed a second time to remove excess labeling reagent.

In vitro $B$ cell assays. Purified B cells were incubated (1 hour, RT) in medium (RPMI, $10 \%$ FCS ) prior to beginning the assay. Cells $\left(0.2 \times 10^{6}\right)$ were plated in U-bottom 96 -well culture plates (Falcon). Liposomes ( $5 \mu \mathrm{M}$ lipid final concentration) were added, and cells were incubated $\left(37^{\circ} \mathrm{C}\right)$ for vari- ous lengths of time. For flow cytometry analysis, cells were centrifuged ( $270 \mathrm{~g}, 7$ minutes) and incubated with the appropriate antibodies in $50 \mu \mathrm{l}$ of FACS buffer (HBSS containing $0.1 \%$ BSA and 2 mM EDTA). After staining $\left(30\right.$ minutes, $\left.4^{\circ} \mathrm{C}\right)$, cells were washed once with $220 \mu \mathrm{l}$ of FACS buffer and resuspended in FACS buffer containing $1 \mathrm{~g} / \mathrm{ml}$ propidium iodide prior to analyzing by flow cytometry. One exception was annexin $\mathrm{V}$ staining, which was carried out in buffer supplied by the manufacturer (Biolegend). Flow cytometry was carried out on a FACSCalibur flow cytometer (BD) and an LSRII flow cytometer (BD). Labeled antibodies for flow cytometry were obtained from Biolegend and BD Biosciences.

In vivo $B$ cell proliferation assays. CFSE-labeled IgM $\mathrm{M}^{\mathrm{HEL}}$ cells were resuspended at a concentration of $10 \times 10^{6}$ cells $/ \mathrm{ml}$ in HBSS, and $200 \mu \mathrm{l}\left(2 \times 10^{6} \mathrm{cells}\right)$ was injected into recipient mice via the tail vein. The following day, liposomes were injected via the tail vein. Four days later, the spleens of the recipient mice were harvested to analyze the CFSE staining of $\mathrm{Ly} 5^{\mathrm{a}+} \mathrm{IgM}^{\mathrm{a}+} \mathrm{B}$ cells.

Calcium flux. Purified B cells were resuspended at $15 \times 10^{6}$ cells $/ \mathrm{ml}$ in RPMI medium containing 1\% FCS, $10 \mathrm{mM}$ HEPES, $1 \mathrm{mM} \mathrm{MgCl}_{2}, 1 \mathrm{mM}$ EGTA, and $1 \mu \mathrm{M}$ Indo-1 (Invitrogen). Cells were incubated in a $37^{\circ} \mathrm{C}$ water incubator for 30 minutes. Following incubation $\left(37^{\circ} \mathrm{C}, 30\right.$ minutes), a 5 -fold volume of the same buffer (without Indo-1) was added and the cells were centrifuged ( $270 \mathrm{~g}, 7$ minutes). For experiments involving human B cells, cells were stained with the appropriate antibodies for 20 minutes on ice in HBSS containing $3 \%$ FCS. To analyze human naive B cells, the cells were stained with anti-CD27 and anti-CD38. To analyze human memory B cells, cells were stained with anti-CD38, anti-IgM, and anti-IgD. Cells were washed and resuspended at a concentration of $2 \times 10^{6}$ cells $/ \mathrm{ml}$ in HBSS containing $1 \% \mathrm{FCS}, 1 \mathrm{mM} \mathrm{MgCl}_{2}$, and $1 \mathrm{mM} \mathrm{CaCl}_{2}$. Cells were stored on ice, and an aliquot $\left(0.5 \mathrm{ml} ; 1 \times 10^{6}\right.$ cells $)$ was warmed $\left(37^{\circ} \mathrm{C}, 5 \mathrm{~min}\right.$ utes) prior to initiating calcium flux measurements. Cells were stimulated with liposomes (ranging from 5-50 $\mu \mathrm{M}$ ), and Indo-1 fluorescence (violet vs. blue) was monitored by flow cytometry (500-1000 events/s) for 3-6 minutes at $37^{\circ} \mathrm{C}$. Stimulation always took place 10 seconds after starting acquisition so that background could be established. Data were analyzed using FlowJo using the kinetics functions. 
A
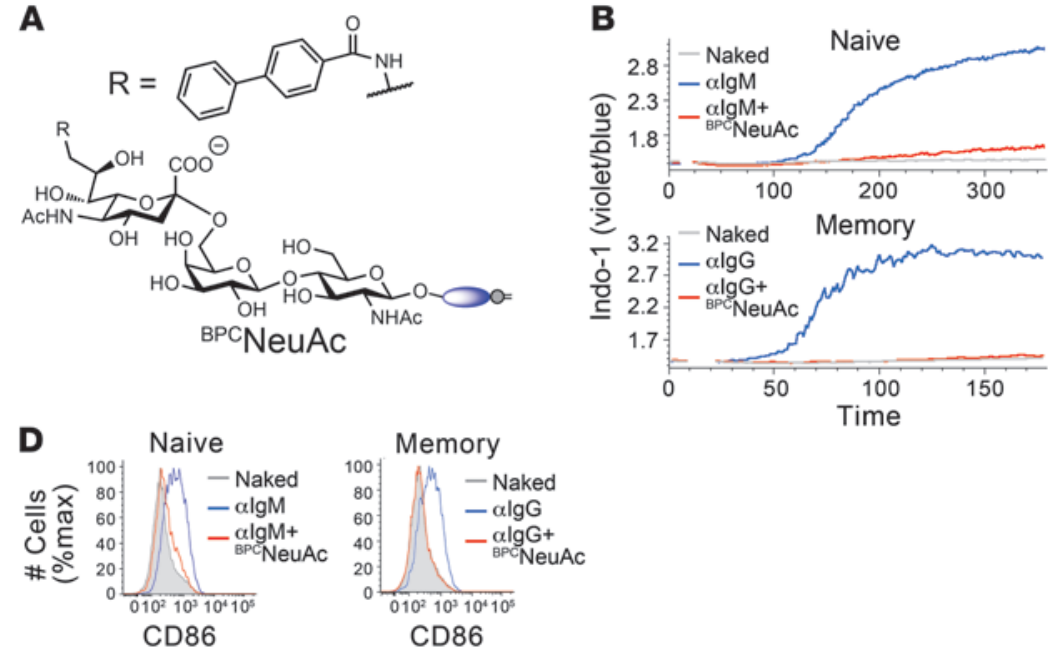

C
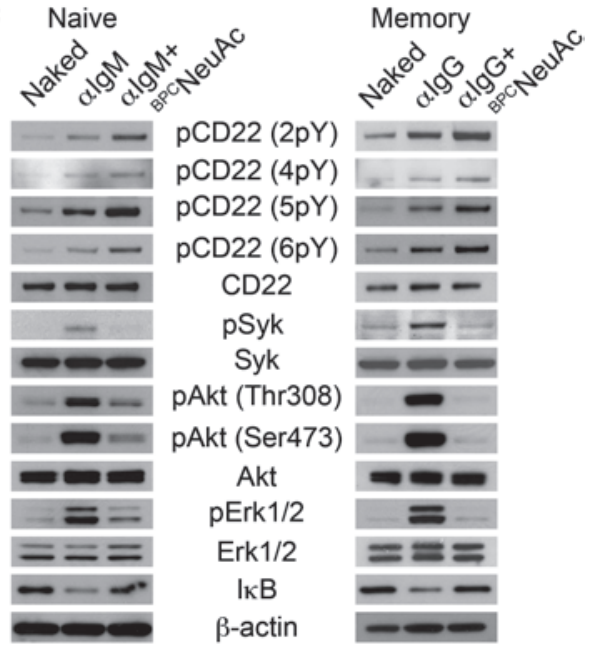

$\mathbf{F}$

E
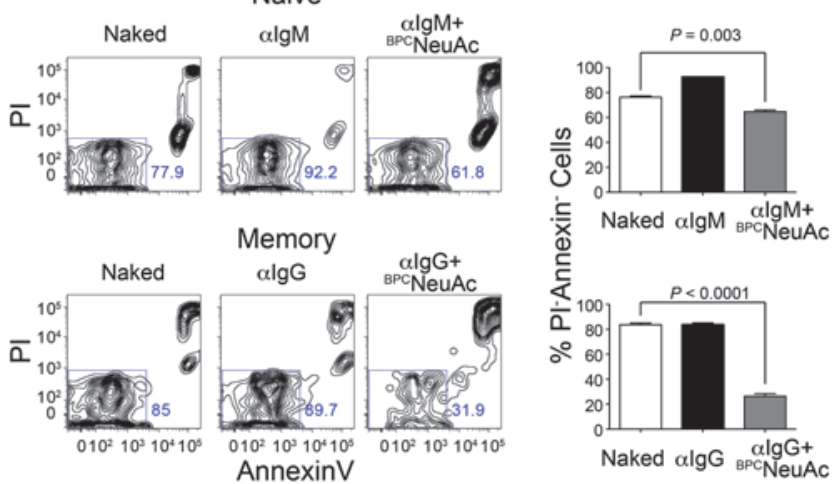

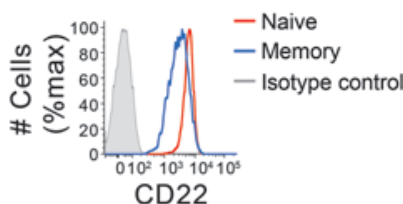

CD22

\section{Figure 6}

STALS induce apoptosis in naive and memory human B cells. (A) Structure of the high-affinity human CD22 ligand BPCNeuAc. (B-D) Activation of naive and memory human B cells is inhibited by copresentation of BPCNeuAc with cognate antigen (anti-IgM or anti-lgG, respectively) on liposomes, as judged by calcium flux (B), Western blot analysis of BCR signaling components (C), and CD86 upregulation (D). (E) Liposomes displaying cognate antigen and hCD22 ligands decrease viability of both naive and memory human B cells. Data represent mean \pm SEM $(n=3)$. A 2-tailed Student's $t$ test was used to establish the level of significance. (F) Staining of naive (red) and memory (blue) human B cells with antiCD22 or isotype control (gray) antibodies. Data are representative of 3 healthy donors.

ELISAs. Maxisorp plates were coated $\left(\mathrm{O} / \mathrm{N}, 4^{\circ} \mathrm{C}\right)$ with the relevant protein $(50 \mu \mathrm{l} /$ well, $10 \mu \mathrm{g} / \mathrm{ml})$ in PBS. $\mathrm{NP}_{4-7}$-BSA in PBS (Biosearch Technologies) was used to look for anti-NP antibodies. The following day, plates were washed twice in TBS-T $(0.1 \%$ Tween 20$)$ and blocked ( 1 hour, RT) with TBS-T containing $1 \%$ BSA. Serum was initially diluted between 20 and 10,000-fold and diluted in 2- to 3-fold serial dilution 8 times on the ELISA plate. Plates were incubated $\left(1\right.$ hour, $\left.37^{\circ} \mathrm{C}\right)$ with serum $(50 \mu \mathrm{l} /$ well $)$, washed 4 times, and incubated $\left(1\right.$ hour, $\left.37^{\circ} \mathrm{C}\right)$ with the appropriate HRPconjugated secondary antibodies (1:2000; Santa Cruz Biotechnology Inc.). Following 5 washes, plates were developed (RT, 15 minutes) in $75 \mu \mathrm{l} /$ well of TMB substrate (Thermo Fisher) and quenched with $75 \mu \mathrm{l} /$ well of $2 \mathrm{~N}$ $\mathrm{H}_{2} \mathrm{SO}_{4}$. Absorbance was measured at $450 \mathrm{~nm}$, and the endpoint titer was calculated as the dilution of serum that produced an absorbance 2 -fold above background.

Western blotting. Purified B cells $\left(30 \times 10^{6} /\right.$ condition $)$ were incubated $\left(37^{\circ} \mathrm{C}, 1\right.$ hour) in medium (RPMI, $\left.3 \% \mathrm{FCS}\right)$ prior to stimulating the cells. Liposomes (5 $\mu \mathrm{M}$ lipid final concentration) were added to cells, and after a 3 or 30 minute incubation $\left(37^{\circ} \mathrm{C}\right)$, cells were centrifuged $(13,000 \mathrm{~g}, 8$ seconds), washed with cold PBS, centrifuged, and lysed $\left(4^{\circ} \mathrm{C}, 30\right.$ minutes) in $280 \mu \mathrm{l}$ of lysis buffer $(20 \mathrm{mM}$ Tris, $150 \mathrm{NaCl}, 1$ mM EDTA, $1 \%$ Triton-X 100, $10 \mathrm{mM} \mathrm{NaF}, 2 \mathrm{mM}$ sodium orthovanadate, protease inhibitor cocktail [Roche], $\mathrm{pH} 7.5$ ). Cell debris was removed by centrifugation $\left(13,000 \mathrm{~g}, 10\right.$ minutes, $\left.4^{\circ} \mathrm{C}\right)$. SDS-PAGE loading buffer was added and samples denatured $\left(75^{\circ} \mathrm{C}, 15\right.$ minutes). Samples were run on $4 \%-12 \%$ gradient SDS-PAGE gels (Invitrogen) and transferred to nitrocellulose. Membranes were blocked (RT, 1 hour) in 5\% nonfat milk powder dissolved in TBS-T and probed with primary antibody $(\mathrm{O} / \mathrm{N}$, $4^{\circ} \mathrm{C}$ ) in TBS-T containing $1 \%$ BSA. Primary antibodies were obtained from Cellular Signaling Technologies and used at a dilution of 1:1000. Phosphospecific CD22 antibodies were a gift from M. Fujimoto (University of Tokyo, Tokyo, Japan) (50). The next day, membranes were washed ( $4 \times 5$ minutes), blocked ( 30 minutes, RT), and probed ( 1 hour, RT) with secondary HRP-conjugated antibodies (1:10,000 dilution; Santa Cruz Biotechnology Inc.). Following 4 washes, blots were incubated ( $2 \mathrm{~min}$ utes, RT) with developing solution (GE Healthcare) and exposed to film.

Microscopy. Purified IgM ${ }^{\text {HEL }}$ B cells were stimulated in the same manner as used for the Western blot analysis for 2 hours. Following stimulation, cells were pelleted ( $0.5 \mathrm{~g}, 3$ minutes), washed with cold PBS, and 
again gently centrifuged. The pellet was resuspended in $1 \mathrm{ml}$ of cold $4 \%$ PFA and rotated $\left(4^{\circ} \mathrm{C}, 10\right.$ minutes). Cells were gently centrifuged and the pellet resuspended in $200 \mu \mathrm{l}$ of PBS. Resuspended cells $(50 \mu \mathrm{l}$, $3 \times 10^{6}$ cells) were dispersed onto polylysine slides (Fisher). After drying, the slides were washed 3 times with PBS and permeabilized with $5 \%$ Triton-X 100 (5 minutes, RT), followed by blocking with 5\% normal goat serum (NGS) (30 minutes, RT). Slides were probed with anti-FoxO1 or anti-FoxO3a (Cellular Signaling Technologies) at a concentration of $1: 80$ in solution of $1 \%$ NGS containing $0.01 \%$ Triton $\mathrm{X}-100\left(\mathrm{O} / \mathrm{N}, 4^{\circ} \mathrm{C}\right)$. Next day, slides were wash 3 times with PBS and probed with Alexa Fluor 488-conjugated goat anti-rabbit (1:1000; Invitrogen) and Alexa Fluor 555 -phalloidin (1:40; Invitrogen) in 1\% NGS. Following 3 washes with PBS, slides were incubated with a solution of DAPI and mounted in Prolong Anti-Fade Medium (Invitrogen). Imaging of the cells was carried out on a Zeiss confocal microscope.

Protein-lipid conjugation. Proteins were conjugated to pegylated distearoylphosethanolamine (PEG-DSPE) using maleimide chemistry (31). A thiol group was introduced using the heterobifunctional crosslinker $N$-succinimidyl 3-(2-pyridyldithio)-propionate (SPDP) (Pierce). Approximately 2.5 molar equivalents of SPDP (in DMSO) were added to a protein solution (in PBS). The reaction was gently rocked (RT, 1 hour). The protein was desalted on a sephadex G-50 column and treated with 25 mM DTT (10 minutes, RT). The amount of released thiol 2-pyridyl was quantified by absorbance at $343 \mathrm{~nm}$ to calculate the extent of protein modification. Following desalting, the thiol-derivatized protein (in the range of 5-50 $\mu \mathrm{M}$ ) was immediately reacted with Maleimide-PEG 2000 -DSPE (200 $\mu \mathrm{M}$; NOF America) under nitrogen (RT, O/N). Lipid-modified proteins were purified from unmodified protein on a sephadex G-100 column and stored at $4{ }^{\circ} \mathrm{C}$. SDS-PAGE was used to verify that proteins were modified by lipid by an increase in their apparent MW on the gel (Supplemental Figure 1). Using these reaction conditions, proteins were modified with between 1 to 3 lipids.

Sugar-lipid conjugation. The high-affinity murine CD22 ligand (BPANeuGc) and human CD22 ligand (BPCNeuAc) were attached to PEGDSPE by coupling 9- $N$-biphenylacetyl-NeuGco2-6Gal $\beta 1-4 G l c N A c-$ $\beta$-ethylamine or 9-N-biphenylcarboxyl-NeuAc $\alpha 2-6 \mathrm{Gal} \beta 1-4 \mathrm{GlcNAc}-$ $\beta$-ethylamine to NHS-PEG 2000 -DSPE (NOF), respectively, as described previously (30). NP-PEG 2000 -DSPE was synthesized under similar conditions through 4-hydroxy-3-nitrophenylacetyl-O-succinimide with amine$\mathrm{PEG}_{2000}$-DSPE (NOF).

Liposomes. All liposomes were composed of a 60:35:5 molar ratio of distearoyl phosphatidylcholine (DSPC) (Avanti Polar Lipids), cholesterol (Sigma-Aldrich), and pegylated lipids. The total molar fraction of pegylated lipids was always kept at $5 \%$; made up of the appropriate combination $\mathrm{PEG}_{2000}$-distearoyl phosphoethanolamine, where $\mathrm{PEG}_{2000}$ indicates polyethylene glycol (PEG-DSPE) (Avanti Polar Lipids), ${ }^{\text {BPANeuGc-PEG }}{ }_{2000^{-}}$ DSPE, ${ }^{{ }^{B P C}} \mathrm{NeuAc}-\mathrm{PEG}_{2000}$-DSPE, NP-PEG 2000 -DSPE, or protein- $\mathrm{PEG}_{2000^{-}}$ DSPE. To assemble the liposomes, DSPC and cholesterol (dissolved in chloroform) were evaporated with nitrogen. ${ }^{\text {BPA NeuGc-PEG }}{ }_{2000}$-DSPE,
${ }^{{ }^{B P C}}{ }_{\mathrm{NeuAc}}-\mathrm{PEG}_{2000}-\mathrm{DSPE}$, and NP-PEG $2000-\mathrm{DSPE}$, from DMSO stocks, were added to the dried lipid and this mixture was lyophilized. The dried lipids were hydrated in PBS (1-10 mM lipid) and sonicated vigorously for a minimum of $5 \times 30$ seconds. Protein-PEG 2000 -DSPE was added at the time of hydration. The molar fraction of the protein on the liposome varied during our studies from $0.0033 \%-0.33 \%$. Liposomes were passed a minimum of 20 times through $800-\mathrm{nm}, 200-\mathrm{nm}$, and 100-nm filters using a handheld mini-extrusion device (Avanti Polar Lipids). Extrusion was carried at $40-45^{\circ} \mathrm{C}$. The diameters of the liposomes were measured on a zetasizer (Malvern) and were consistently in the range of 100 to $130 \pm 30 \mathrm{~nm}$. For studies with NP as the antigen, liposomes contained 0.5 mol\% NP (concentration based on lipid content). Mice received 2001 of $2.5 \mathrm{mM}$ liposomes. For studies with HEL as the antigen in C57BL/6J mice, liposomes contained $0.1 \mathrm{~mol} \%$ and mice received $200 \mu \mathrm{l}$ of $1 \mathrm{mM}$ liposomes. For studies with HEL as the antigen in BALB/c mice, the molar fraction and absolute amount of liposomes used during the immunization were optimized according to Supplemental Figure 6. Optimized conditions, which were also used for OVA, MOG, and FVIII, contained $0.01 \mathrm{~mol} \%$, and mice received $200 \mu \mathrm{l}$ of $10 \mu \mathrm{M}$ liposomes. For in vitro experiments with $\mathrm{IgM}^{\mathrm{HEL}}$ B cells and human primary B cells, liposomes contained $0.1 \mathrm{~mol} \% \mathrm{HEL}$ and anti-Ig, respectively, and cells were incubated with $10 \mathrm{M}$ liposomes. All STALs contained $1 \mathrm{~mol} \%$ CD22 ligand, except in Figure 1E, where the ligand/mol ratio was titrated.

Statistics. Statistical significance was determined using an unpaired 2-tailed Student's $t$ test. $P<0.05$ was considered significant.

Study approval. The TSRI IACUC approved all experimental procedures involving mice. Procedures involving human subjects were reviewed and approved by the TSRI IRB. Subjects provided informed consent prior to their participation in the study.

\section{Acknowledgments}

We thank Jessica Lu, Jeffel Medina, and Britni Arlian Cruz for technical help; Julie Pilotte for assistance with microscopy; David Nemazee for helpful discussions in the early stages of this work; Fred Aswad of Bayer Healthcare for providing hrFVIII; and Anna Tran-Crie for assistance in preparation of the manuscript. M.S. Macauley is supported by a fellowship from the Human Frontiers Scholarship Program. F. Pfrengle is supported by a fellowship from the Deutscher Akademischer Austausch Dienst (DAAD). C. Rademacher wishes to thank EMBO for a long-term fellowship. This work is funded by grants from the NIH (R01AI050143 and R01AI099141).

Received for publication February 4, 2013, and accepted in revised form April 4, 2013.

Address correspondence to: James C. Paulson, 10550 N. Torrey Pines Rd., MEML71, La Jolla, California 92037, USA. Phone: 858.784.9634; Fax: 858.784.9690; E-mail: jpaulson@scripps.edu.
1. Naparstek Y, Plotz PH. The role of autoantibodies in autoimmune disease. Annu Rev Immunol. 1993;11:79-104.

2. Kwun J, et al. The role of B cells in solid organ transplantation. Semin Immunol. 2012;24(2):96-108.

3. Gould HJ, Sutton BJ. IgE in allergy and asthma today. Nat Rev Immunol. 2008;8(3):205-217.

4. Singh SK. Impact of product-related factors on immunogenicity of biotherapeutics. J Pharm Sci. 2011;100(2):354-387.

5. Vassilopoulos D, Calabrese LH. Risks of immunosuppressive therapies including biologic agents in patients with rheumatic diseases and co-existing chronic viral infections. Curr Opin Rheumatol. 2007;19(6):619-625.

6. Gea-Banacloche JC. Rituximab-associated infections. Semin Hematol. 2010;47(2):187-198.

7. Miller SD, Turley DM, Podojil JR. Antigen-specific tolerance strategies for the prevention and treatment of autoimmune disease. Nat Rev Immunol. 2007;7(9):665-677.

8. Sabatos-Peyton CA, Verhagen J, Wraith DC. Antigen-specific immunotherapy of autoimmune and allergic diseases. Curr Opin Immunol. 2010;22(5):609-615.

9. Hay CR, DiMichele DM. The principal results of the International Immune Tolerance Study: a randomized dose comparison. Blood. 2012;119(6):1335-1344.

10. Skupsky J, Su Y, Lei TC, Scott DW. Tolerance induction by gene transfer to lymphocytes. Curr Gene Ther. 2007;7(5):369-380.

11. Smarr CB, Hsu CL, Byrne AJ, Miller SD, Bryce PJ. Antigen-fixed leukocytes tolerize Th2 responses in mouse models of allergy. J Immunol. 2011;187(10):5090-5098.

12. Zhang HG, et al. Induction of specific T-cell tolerance by adenovirus-transfected, Fas ligandproducing antigen presenting cells. Nat Biotechnol. 
1998;16(11):1045-1049.

13. Rynda-Apple A, Huarte E, Maddaloni M, Callis G, Skyberg JA, Pascual DW. Active immunization using a single dose immunotherapeutic abates established EAE via IL-10 and regulatory T cells. Eur J Immunol. 2011;41(2):313-323.

14. Miller A, Lider O, Roberts AB, Sporn MB, Weiner HL. Suppressor T cells generated by oral tolerization to myelin basic protein suppress both in vitro and in vivo immune responses by the release of transforming growth factor beta after antigen-specific triggering. Proc Natl Acad Sci US A. 1992;89(1):421-425.

15. Vaughan AT, Roghanian A, Cragg MS. B cells masters of the immunoverse. Int J Biochem Cell Biol. 2011;43(3):280-285.

16. Barr TA, Gray M, Gray D. B cells: programmers of CD4 T cell responses. Infect Disord Drug Targets. 2012;12(3):222-231.

17. Tsubata T. Role of inhibitory BCR co-receptors in immunity. Infect Disord Drug Targets. 2012;12(3):181-190.

18. Crocker PR, Paulson JC, Varki A. Siglecs and their roles in the immune system. Nat Rev Immunol. 2007;7(4):255-266

19. Jellusova J, Nitschke L. Regulation of B cell functions by the sialic acid-binding receptors siglec-G and CD22. Front Immunol. 2011;2:96.

20. Pillai S, Netravali IA, Cariappa A, Mattoo H. Siglecs and immune regulation. Annu Rev Immunol. 2012;30:357-392.

21. Jellusova J, Wellmann U, Amann K, Winkler TH, Nitschke L. CD22 x Siglec-G double-deficient mice have massively increased B1 cell numbers and develop systemic autoimmunity. J Immunol. 2010;184(7):3618-3627.

22. Doody GM, et al. A role in B cell activation for CD22 and the protein tyrosine phosphatase SHP. Science. 1995;269(5221):242-244.

23. Smith KG, Tarlinton DM, Doody GM, Hibbs ML, Fearon DT. Inhibition of the B cell by CD22: a requirement for Lyn.J Exp Med. 1998;187(5):807-811.

24. Collins BE, Smith BA, Bengtson P, Paulson JC. Ablation of CD22 in ligand-deficient mice restores B cell receptor signaling. Nat Immunol. 2006;7(2):199-206

25. Grewal PK, et al. ST6Gal-I restrains CD22-dependent antigen receptor endocytosis and Shp-1 recruitment in normal and pathogenic immune signaling. Mol Cell Biol. 2006;26(13):4970-4981.

26. Weintraub BC, Jun JE, Bishop AC, Shokat KM, Thomas ML, Goodnow CC. Entry of B cell receptor into signaling domains is inhibited in tolerant B cells. J Exp Med. 2000;191(8):1443-1448.

27. Lanoue A, Batista FD, Stewart M, Neuberger MS. Interaction of CD22 with alpha2,6-linked sialoglycoconjugates: innate recognition of self to dampen B cell autoreactivity? Eur J Immunol. 2002;32(2):348-355.

28. Duong BH, et al. Decoration of T-independent antigen with ligands for CD22 and Siglec-G can suppress immunity and induce B cell tolerance in vivo. J Exp Med. 2010;207(1):173-187.

29. Courtney AH, Puffer EB, Pontrello JK, Yang ZQ Kiessling LL. Sialylated multivalent antigens engage CD22 in trans and inhibit B cell activation. Proc Natl Acad Sci U S A. 2009;106(8):2500-2505.

30. Chen WC, Completo GC, Sigal DS, Crocker PR, Saven A, Paulson JC. In vivo targeting of B-cell lymphoma with glycan ligands of CD22. Blood. 2010;115(23):4778-4786.

31. Loughrey HC, Choi LS, Cullis PR, Bally MB. Optimized procedures for the coupling of proteins to liposomes. J Immunol Methods. 1990;132(1):25-35.

32. Shek PN, Heath TD. Immune response mediated by liposome-associated protein antigens. III. Immunogenicity of bovine serum albumin covalently coupled to vesicle surface. Immunology. 1983;50(1):101-106.

33. Collins BE, et al. High-affinity ligand probes of CD22 overcome the threshold set by cis ligands to allow for binding, endocytosis, and killing of $\mathrm{B}$ cells. J Immunol. 2006;177(5):2994-3003.

34. Goodnow CC, et al. Altered immunoglobulin expression and functional silencing of self-reactive B lymphocytes in transgenic mice. Nature. 1988;334(6184):676-682

35. Peng SL. Immune regulation by Foxo transcription factors. Autoimmunity. 2007;40(6):462-469.

36. Rawle FE, et al. Heterogeneity of the immune response to adenovirus-mediated factor VIII gene therapy in different inbred hemophilic mouse strains. J Gene Med. 2004;6(12):1358-1368.

37. Blixt O, Collins BE, van den Nieuwenhof IM, Crocker PR, Paulson JC. Sialoside specificity of the siglec family assessed using novel multivalent probes: identification of potent inhibitors of myelin-associated glycoprotein. J Biol Chem.
2003;278(33):31007-31019.

38. Peaker CJG, Neuberger MS. Association of Cd22 with the B-cell antigen receptor. Eur J Immunol. 1993;23(6):1358-1363.

39. Srinivasan L, et al. PI3 kinase signals BCR-dependent mature B cell survival. Cell. 2009;139(3):573-586.

40. Calamito $M$, et al. Akt1 and Akt2 promote peripheral B-cell maturation and survival. Blood. 2010;115(20):4043-4050.

41. Brennan FM, Chantry D, Jackson A, Maini R, Feldmann M. Inhibitory effect of TNF alpha antibodies on synovial cell interleukin-1 production in rheumatoid arthritis. Lancet. 1989;2(8657):244-247.

42. Harding FA, Stickler MM, Razo J, DuBridge RB. The immunogenicity of humanized and fully human antibodies: residual immunogenicity resides in the CDR regions. MAbs. 2010;2(3):256-265.

43. Lusher JM, Arkin S, Abildgaard CF, Schwartz RS. Recombinant factor VIII for the treatment of previously untreated patients with hemophilia A. Safety, efficacy, and development of inhibitors. Kogenate Previously Untreated Patient Study Group. N Engl J Med. 1993;328(7):453-459.

44. Iorio A, et al. Rate of inhibitor development in previously untreated hemophilia A patients treated with plasma-derived or recombinant factor VIII concentrates: a systematic review. J Thromb Haemost. 2010;8(6):1256-1265.

45. Poe JC, Tedder TF. CD22 and Siglec-G in B cell function and tolerance. Trends Immunol. 2012;33(8):413-420.

46. Wakabayashi C, Adachi T, Wienands R, Tsubata $\mathrm{T}$. A distinct signaling pathway used by the IgG-containing B cell antigen receptor. Science. 2002;298(5602):2392-2395.

47. Waisman A, et al. IgG1 B cell receptor signaling is inhibited by CD22 and promotes the development of B cells whose survival is less dependent on Ig alpha/beta. J Exp Med. 2007;204(4):747-758.

48. Horikawa K, et al. Enhancement and suppression of signaling by the conserved tail of IgG memory-type B cell antigen receptors. J Exp Med. 2007;204(4):759-769.

49. Mei B, et al. Rational design of a fully active, longacting PEGylated factor VIII for hemophilia A treatment. Blood. 2010;116(2):270-279.

50. Fujimoto $M$, et al. B cell antigen receptor and CD40 differentially regulate CD22 tyrosine phosphorylation. J Immunol. 2006;176(2):873-879. 